\title{
A CASE REPORT \\ MULTIFOCAL PULMONARY AND LIVER \\ ABSCESSES DUE TO KLEBSIELLA PNEUMONIAE INFECTION IN A LAMB IN SIDI-BARRANI CITY, MATROUH GOVRNORATE, EGYPT
}

\author{
Wassif, Islam M.* and Adel M. El-Kattan \\ Department of Animal Health, Desert Research Center, Cairo, Egypt \\ *E-mail: islam_wassif@hotmail.com
}

T ambs mortality was noticed in Sidi-Barrani City,

Matrouh Governorate, Egypt during winter season, 2014

- 2015. One of them, a three-month-old female lamb died after signs of fever accompanied with some respiratory manifestations firstly and dullness, inability to move and weight loss for over seven days later, without response to tetracycline treatment. Necropsy revealed multifocal caseous abscesses in the lungs and liver. Klebsiella pneumoniae was isolated from these lesions. The bacterial isolate was resistant to Tetracyclin (in vitro), which is the most common used antimicrobial agent for animal treatment in this region. On the other hand, it was susceptible to Gentamycin and Chloramphenicol.

Keywords: Klebsiella pneumoniae, lamb, lung, liver, abscesses

Klebsiella pneumoniae is enteric gram-negative bacillus (Abbott, 1999), that is considered as an opportunistic bacteria, which rarely causes enteric disease in domestic animals. Klebsiella pneumoniae has ability to circumvent host defense mechanisms, to colonizes it and survives in affected organs as it produce abundant capsular material, which may inhibit phagocytosis (Quinn et al., 1994). Lung abscesses are common in sheep, but are difficult to diagnose it only by clinical examination of diseased animal. Sheep with lung abscesses generally show poor body conditions, and are often dull and depressed (Abubakr et al., 1981). Pyogenic infection in sheep is a serious health problem, and can even cause death of the affected animal (Addo and Dennis, 1977). Pneumonia with pulmonary abscesses caused by Pasteurella multocida, and Staphylococcus aureus, as well as Trueperella pyogenes (formerly Arcanobacterium pyogenes), Corynebacterium pseudotuberculosis, and Klebsiella pneumoniae have been reported in sheep (Anderson et al., 2002 and Azizi et al., 2013). Also, Klebsiella pneumoniae was isolated primarily from liver abscess in human cases with generalized metastatic complications (Fang et al., 2004). 


\section{MATERIALS AND METHODS}

\section{Case History}

In Sidi-Barrani City, Matrouh Governorate, Egypt, which is about 95 $\mathrm{km}$ east of the border with Libya $\left(31^{\circ} 36^{\prime} 39^{\prime \prime} \mathrm{N} 25^{\circ} 55^{\prime} 32^{\prime \prime} \mathrm{E}\right)$, as a village is mainly a Bedouin community. Winter, 2014-2015, a three-month-old female lamb died after signs of fever accompanied with respiratory manifestations firstly and dullness, inability to move and weight loss for over 7 days later without response to tetracycline treatment. This lamb belongs to a group of lambs that had the same clinical signs, which are bred at open housing system in this region characterized by cold weather present in this period of the year (as a potential stress factor). Necropsy revealed moderate diffuse pulmonary edema and multifocal, caseous abscesses in both lungs and liver. No gross pathological changes were detected in any other organs or tissues.

\section{Bacteriological Examination}

Abscess contents from different areas of the lungs and liver, were aseptically collected and plated on blood and MacConkey media, and incubated aerobically at $37^{\circ} \mathrm{C}$. Culture plates were examined daily for three days. The growth was classified as heavy, moderate, and light (three or less colonies were considered insignificant, most probably contaminant). Primary isolated and suspected colonies were sub cultivated to obtain pure cultures, and were identified as Klebsiella pneumoniae based on standard procedures; such as colonial morphology, gram stain and classical biochemical characteristics (cytochrome oxidase, catalase, indole production, urease production, sulfhydric acid production on T.S.I. medium (oxoid) and oxidation / fermentation tests (Quinn et al., 1994). The antimicrobial susceptibility testing was carried out by disk diffusion test, using ten standard antimicrobial discs (oxoid), which were Ceftriaxon $(30 \mu \mathrm{g})$, Ceftazidime $(30 \mu \mathrm{g})$, Imipenem $(10 \mu \mathrm{g})$, Aztreonam $(30 \mu \mathrm{g})$, Gentamycin $(10 \mu \mathrm{g})$, Amikacin $(30 \mu \mathrm{g})$, Ciprofloxacin $(5 \mu \mathrm{g})$, Chloramphenicol $(30 \mu \mathrm{g})$, Co-trimoxazole $(25 \mu \mathrm{g})$ and Tetracycline $(30 \mu \mathrm{g})$. After preparation of the standardized inoculum with sterile nutrient broth (density 0.5 McFerland), Muller Hinton agar (oxoid) plate was inoculated with even distribution of the bacterial suspension all over the plate. Then, using the pointed forceps, the antimicrobial discs were applied onto the surface of inoculated plate, which was then incubated at $37^{\circ} \mathrm{C}$ for 24 hours. The degree of susceptibility was determined by measuring of the zone of growth inhibition (in $\mathrm{mm}$ ) and the results were interpreted according to the CLSI (formerly NCCLS) standard (CLSI, 2010). 


\section{RESULTS AND DISCUSSION}

Little published reports indicated that Klebsiella pneumoniae has caused multiple pulmonary and liver abscesses in sheep, thus this report proved that this microorganism can cause multiple abscesses in the lungs and liver of young lambs. However, it has been known to cause lung abscesses in adult sheep as recorded by Azizi et al. (2013), who isolated Klebsiella pneumoniae from the pulmonary abscesses of slaughtered sheep in Iran. Also, Gameel et al. (1991) recovered Klebsiella pneumoniae subspecies ozaenae from small nodules on the chest wall and lungs of sheep slaughtered in Al-Ahsa abattoir, Saudi Arabia. In addition, Boguta et al. (2002) identified Klebsiella pneumoniae and Escherichia coli from purulent bronchopneumonia of foal necropsy. Donia et al. (2014) reported that Klebseilla pneumoniae was the most dominant isolate $(27.3 \%)$ from pneumonic sheep lungs. They added that Klebseilla pneumoniae infection is characterized by presence of metal ions (a virulence factor), which is highly crucial for its survival.

Isolation of Klebsiella pneumoniae from pulmonary and liver abscess in this report goes hand to hand with a findings of Fang et al. (2004), who found that Klebsiella pneumoniae is a common cause of lung and liver abscesses in immune-compromised human patients with chronic lung disease, malignancies, urinary tract infections, septicemia, soft tissue infections and or diabetes mellitus. On the other hand, Hatem et al. (2013) claimed that further investigations may be needed to ensure if Klebsiella has ability to induce abscess itself or it comes as a secondary infection following the primary one since they did not isolate Klebsiella pneumoniae in pure culture in any examined abscess (which, in opposite, did occur in this study).

Pulmonary abscesses may be present in many cases of pneumonia in animals and are not recognizable clinically. When the spread is in hematogenous way, large numbers of small abscesses can develop simultaneously in different body organs and tissues (Radostits et al., 2007), which in our case was evidenced in the liver of the dead animal.

Results in table (1) show the susceptibility of isolated Klebsiella strain to many antimicrobial agents, including Ceftriaxon, Ceftazidime, Imipenem, Aztreonam, Gentamycin, Amikacin, Ciprofloxacin and Chloramphenicol, and the resistance to Co-trimoxazole and Tetracycline. Tetracycline is the most common used antimicrobial agent in this region and is used for treatment of respiratory infections in sheep, which explain the incurable cases after Tetracycline treatment in this field problem. 
Table (1). The susceptibility of isolated Klebseilla pneumoniae to antimicrobial agents.

\begin{tabular}{cccccc}
\hline \multirow{2}{*}{$\begin{array}{l}\text { Antimicrobial } \\
\text { agent }\end{array}$} & $\begin{array}{c}\text { Conc. } \\
\text { in the }\end{array}$ & \multirow{2}{*}{$\begin{array}{c}\text { Zone of } \\
\text { inhibition }\end{array}$} & \multicolumn{3}{c}{$\begin{array}{c}\text { Interpretation of results (CLSI formerly } \\
\text { NCCLS standard) }\end{array}$} \\
\cline { 6 - 7 } & $\begin{array}{c}\text { disk } \\
(\boldsymbol{\mu g})\end{array}$ & $(\mathbf{m m})$ & Resistant & Intermediate & Susceptible \\
\hline Ceftriaxon & $\mathbf{3 0}$ & $\mathbf{2 7}$ & $\leq 19$ & $20-22$ & $\geq 23$ \\
\hline Ceftazidime & $\mathbf{3 0}$ & $\mathbf{3 2}$ & $\leq 17$ & $18-20$ & $\geq 21$ \\
\hline Imipenem & $\mathbf{1 0}$ & $\mathbf{2 7}$ & $\leq 13$ & $14-15$ & $\geq 16$ \\
\hline Aztreonam & $\mathbf{3 0}$ & $\mathbf{2 2}$ & $\leq 17$ & $18-20$ & $\geq 21$ \\
\hline Gentamycin & $\mathbf{1 0}$ & $\mathbf{1 6}$ & $\leq 12$ & $13-14$ & $\geq 15$ \\
\hline Amikacin & $\mathbf{3 0}$ & $\mathbf{2 3}$ & $\leq 14$ & $15-16$ & $\geq 17$ \\
\hline Ciprofloxacin & $\mathbf{5}$ & $\mathbf{3 4}$ & $\leq 20$ & $21-30$ & $\geq 31$ \\
\hline Chloramphenicol & $\mathbf{3 0}$ & $\mathbf{2 3}$ & $\leq 12$ & $13-17$ & $\geq 18$ \\
\hline Co-trimoxazole & $\mathbf{2 5}$ & $\mathbf{1 4}$ & $\leq 10$ & $11-15$ & $\geq 16$ \\
\hline Tetracycline & $\mathbf{3 0}$ & $\mathbf{7}$ & $\leq 11$ & $12-14$ & $\geq 15$ \\
\hline
\end{tabular}

\section{CONCLUSION}

Klebsiella pneumoniae has been known to cause pneumonia in adult sheep, but this report discuss its ability to cause extensive abscess lesions in the lungs extending to other vital organ (liver) especially in lambs. Other antimicrobial agents rather than tetracycline should be used in these cases. Further studies are needed for molecular characterization of this bacterial species and immunological response against its infection for vaccine preparation.

\section{REFERENCES}

Abbott, S. (1999). Klebsiella, Enterobacter, Citrobacter and Serratia. In "Manual of Clinical Microbiology". $7^{\text {th }}$ edition (P.R. Murray, E.J. Baron, M.A. Pfaller, F.C. Tenover, and R.H. Yolken, eds.). American Society for Microbiology Press, Washington. D.C., p. 475-482.

Abubakr, M.I., M.E. Elfaki, S.A. Abdalla, and Kamal, S.M. (1981). Pathological studies on sheep and goats pneumonia in the Sudan. II. Experimental infection. Bull. Anim. Health Prod. Afr., 29 (1): 85-94.

Egyptian J. Desert Res., 65, No. 1, 75-80 (2015) 
Addo, P.B. and Dennis S.M. (1977). Corynebacteria associated with diseases of cattle, sheep and goats in northern Nigeria. Br. Vet. J., 133: 334-339.

Anderson, D.E., D.M. Rings and D.G. Pugh (2002). Diseases of the Integumentary System. In "Sheep and Goat Medicine" (Pugh, D.G. ed.), Philadelphia, WB Saunders, p. 197-222.

Azizi, S., S.K. Farzad and O. Ahmad (2013). Pneumonia in slaughtered sheep in south-western Iran: pathological characteristics and aerobic bacterial aetiology. Veterinaria Italiana, 49 (1): 109-118.

Boguta, L., Z. Gradzki, E. Borges, F. Maurin, A. Kodjo and S. Winiarczyk (2002). Bacterial flora in foals with upper respiratory tract infections in Poland. J. Vet. Med. B., 49: 294-297.

CLSI: Clinical and Laboratory Standards Institute (2010). CLSI document M100. Performance Standards for Antimicrobial Susceptibility Testing, $20^{\text {th }}$ edition. Wayne, Pa.

Donia, G.R., I.M. Wassif and I.A. El Ebissy (2014). Impact of some environmental factors and microbes causing respiratory diseases on antioxidant levels in small ruminants. Global Veterinaria, 12 (3): 299-306.

Fang, C., Y. Chuang, C. Shun, S. Chang and J. Town (2004). A novel virulence gene in Klebsiella pneumonia strains causing primary liver abscess and septic metastatic complications. J. Exp. Med., The Rockefeller University Press, 199 (5): 697-705.

Gameel, A.A., S.M. El-Sanousi, F. Al-Nawawi and M.O. Al-Shazly (1991). Association of Klebsiella organisms with pulmonary lesions in sheep. Rev. Elev. Med. Vet. Pays. Trop., 44 (2): 161-164.

Hatem, M.E., R.H. Arab, S. Nagwa, Sherein Abd El-Moez, Eman Khairy and E.A. Fouad, (2013). Bacterial abscessation in sheep and goat in Giza Governorate with full antibiogram screening. Global Veterinaria, 10 (4): 372-381.

Quinn, P. J., M.E. Carter, B.K. Markey and G.R. Carter (1994). In "Veterinary Clinical Microbiology". Mosby-Year Book Limited, $150 \mathrm{pp}$.

Radostits, O.M., C.C. Gay, K.W. Hinchcliff and P.D. Constable (2007). In "Veterinary Medicine-A textbook of the Diseases of Cattle, Horses, Sheep, Pigs and Goats". $10^{\text {th }}$ edition, Elsevier, 517 pp. 


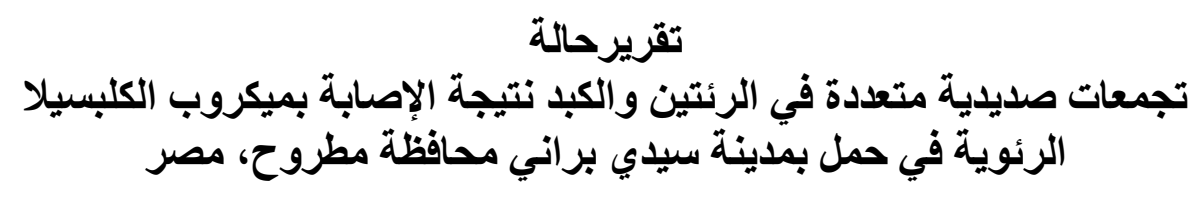

$$
\text { قسم صحة الحيف وان، مركز القطان بحوث الصحر اء، المطرية، القاهرة، مصر }
$$

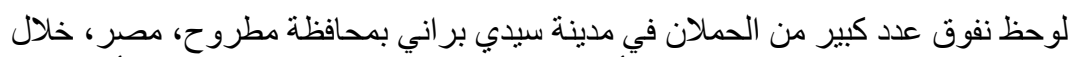

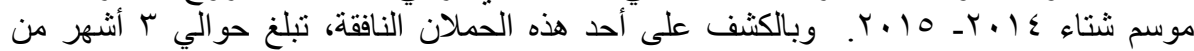

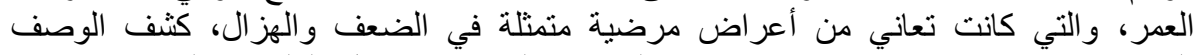

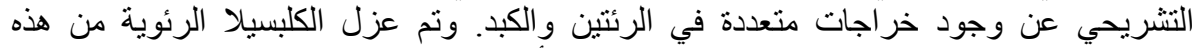

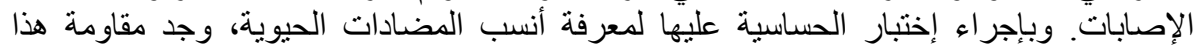

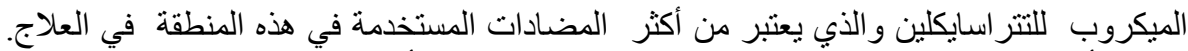

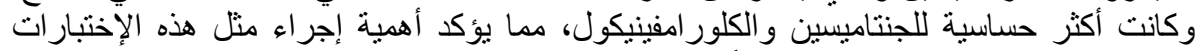

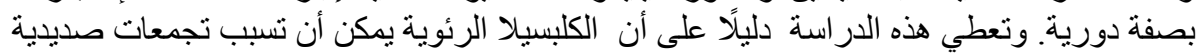
متعددة في الرئتين والكبد في الحملان الصغيرة.

Egyptian J. Desert Res., 65, No. 1, 75-80 (2015) 